\title{
Regimen Used to Treat Gastric Carcinoma
}

National Cancer Institute

\section{Source}

National Cancer Institute. Regimen Used to Treat Gastric Carcinoma. NCI Thesaurus.

Code C63361.

Any regimen that can be used for the treatment of gastric carcinoma. 